\title{
Enfoques republicanos contemporáneos sobre la democracia y su potencial cosmopolita ${ }^{1}$
}

\author{
ISEULT HONOHAN \\ School of Politics and International Relations, \\ University College Dublin
}

RESUMEN. ¿Tiene la teoría política republicana algún recurso que ofrecer a la democracia contemporánea? Dos objeciones son abordadas: que se pone en tela de juicio demasiado internamente que la teoría republicana contemporánea pueda ofrecer una propuesta coherente, y que ninguna idea susceptible de ser valorada es distinguible de la teoría liberal. Mantengo que, a pesar de que hay ciertos lugares comunes entre los republicanos y los liberales, su compromiso para con la democracia muestra diferentes enfoques, tensiones y acuerdos. El republicanismo tiene una subyacente perspectiva coherente y ofrece un enfoque distintivo para fundamentar y concebir la democracia. Su énfasis en la deliberación entre ciudadanos en múltiples esferas públicas, antes que en una soberanía popular unitaria, puede contribuir potencialmente a tratar los problemas que conlleva la compresión y la realización de la democracia a nivel transnacional y global.

Palabras clave: republicanismo, liberalismo, democracia, globalización, cosmopolitismo.
ABSTRACT. Has republican political theory any resources to offer contemporary democracy? Two objections are addressed: that contemporary republican theory is too internally contested to offer a coherent approach, and that any valuable insights are indistinguishable from liberal theory. I argued that, despite certain common ground between republicans and liberals, their engagement with democracy displays different approaches, tensions and accommodations. Republicanism has a coherent underlying perspective and offers a distinctive approach to grounding and conceiving democracy. Its emphasis on deliberation among citizens in multiple public spheres, rather than on unitary popular sovereignity can potentially contribute to addressing problems of understanding and realising democracy at transnational and global levels.

Keywords: republicanism, liberalism, democracy, globalization, cosmopolitism. 


\section{Introducción}

¿Puede ofrecernos la teoría política republicana alguna perspectiva útil o interesante sobre la democracia hoy en día? Abordar esta pregunta implica considerar dos cuestiones: primero, que se pone en tela de juicio demasiado internamente que la teoría republicana contemporánea pueda ofrecer una propuesta coherente; segundo, que sea lo que fuere aquello susceptible de ser valorado en el republicanismo no se distingue de la teoría liberal. Sostendré que, a pesar de que existen ciertos lugares comunes entre ambos, el republicanismo y el liberalismo enfocan la democracia de forma diferente; que denotan diferentes tensiones sobre ciertos aspectos de la democracia, y que llegan a distintas conclusiones. Además, argüiré que aunque el republicanismo contemporáneo sea una teoría puesta en tela de juicio, en ella subyace una visión coherente que ofrece un enfoque alternativo para fundamentar y concebir un modelo de democracia que quizás sea eficaz a la hora de considerar nuevos contextos para la democracia.

Los críticos identifican dos enfoques republicanos contemporáneos que apuntan direcciones opuestas. Un enfoque promociona el valor fundamental de la actividad política (Arendt, 1958) de una manera que se antoja inaceptable en el mundo actual, donde una pluralidad de visiones sobre lo que es importante para la vida humana debe ser adaptada. El otro valora la actividad política de manera instrumental, como un medio para granjearse seguridad personal frente a la dominación, precondición para cualquiera que sea el estilo de vida que los ciudadanos deseen perseguir. En el segundo caso, argumentan los críticos, su compatibilidad con el liberalismo es considerable, mas no ofrece ningún valor añadido.

En lo que sigue, primero trataré de esbozar qué es lo que yo entiendo por republicanismo y en qué se diferencia del liberalismo. Debo decir que en un artículo de estas dimensiones el tratamiento de ambos temas y enfoques deberá ser, de alguna manera, esquemático. Ni el liberalismo ni el republicanismo pueden ser propiamente entendidos como formas de democracia. Identifico, pues, las diferentes tensiones a las que ambas teorías han dado lugar en sus relaciones con la democracia y las conclusiones a las que han llegado. A continuación muestro cómo los argumentos del republicanismo contemporáneo intentan operar más allá de los problemas de los primeros enfoques republicanos, a la par que permanecen lejos de los consensos liberales contemporáneos. Finalmente, considero sucintamente si el republicanismo ofrece recursos para abordar la democracia a nivel transnacional o global.

\section{El republicanismo}

El republicanismo no se opone al valor central del liberalismo, la libertad, sino que es una teoría con un centro de gravedad diferente que se articula en torno a un ramillete de valores como la libertad, la participación en el autogobierno y la solidaridad. Es la unión de estas otras consideraciones de compromiso cívico con la libertad lo que es característico del republicanismo.

El republicanismo, por tanto, se preocupa tanto por la libertad como por el bien común compartido por los ciudadanos. Aborda el problema de la libertad entre seres humanos necesariamente interdependientes. Como respuesta, propone que la libertad, tanto la política como la personal, puede ser realizada a través de la pertenencia a una comunidad política, en la que aquellos que son recíprocamente vulnerables y comparten un mismo sino puedan ser capaces de imprimir alguna dirección colectiva sobre sus vidas de manera conjunta. Al tiempo que algunos republicanos definen la libertad en términos de seguridad como no-dominación, otros lo hacen 
como participación en los procesos de decisión; en ambos casos, la libertad está ligada al autogobierno y la preocupación por el bien común. Este enfoque, más antiguo (e influyente) que el liberalismo, ha sido expresado y desarrollado de múltiples formas. Aun cuando representa una tradición específica en el seno de la política occidental, también representa una posible y socorrida respuesta a aspectos persuasivos de la condición humana.

Las políticas republicanas tratan, por tanto, de habilitar a los interdependientes ciudadanos para que deliberen y satisfagan el bien común de una comunidad política históricamente desarrollada; al menos, tanto como tratan de promocionar los intereses y derechos individuales. Por bien común se entiende aquello que es compartido por los ciudadanos, no como la suma de los bienes individuales. Este énfasis en la responsabilidad para con el bien común es lo que ubica al republicanismo fuera de la esfera de las teorías libertarias que se centran exclusivamente en los derechos individuales. Asimismo, enfatizar que dicho bien común es políticamente realizado coloca al republicanismo al margen del neutralismo de las teorías liberales, las cuales excluyen toda concepción sustantiva sobre los valores y la vida buena de su discurso político. Finalmente, también es importante subrayar que enfatizar la construcción política de la comunidad política distingue a los republicanos de los comunitaristas, quienes conciben la política como la expresión de valores pre-políticos compartidos por una comunidad ${ }^{2}$.

De esta manera, el liberalismo y el republicanismo no pueden ser opuestos simplemente como teorías que patrocinan la libertad y la virtud cívica respectivamente. Ambos se implican en la protección de la libertad por medio del imperio de la ley y alguna suerte de separación de poderes. Sin embargo, mientras los liberales oponen la libertad a la interferencia, los republicanos la oponen a la esclavitud y la dominación. Así, el republicanismo presenta un enfoque característico de la libertad ligado a la idea de autogobierno. Los principales peligros que los republicanos señalan son la dominación -la amenaza de la interferencia arbitraria por parte de un tercero-, y la corrupción -cuando intereses particulares o de facción se anteponen al bien común-. Por el contrario, para los liberales el punto de partida de la política es la amenaza localizada en los conflictos que emergen entre individuos libres e iguales por naturaleza y con distintos intereses materiales y de valores. Dicho estado requiere el establecimiento de una autoridad, lo que, a su vez, constituye una amenaza de tiranía, por lo que la libertad es protegida limitando la interferencia, cualquiera que sea su origen.

\section{El liberalismo y la democracia}

Puede resultar muy duro argüir que no hay nada inherente al liberalismo que nos conduzca hacia una democracia. Sin embargo, su principal preocupación no son tanto las fuentes del poder gubernamental como poner límites a dicho poder. La manera fundamental de abordarlo ha sido por medio de la distinción entre asuntos públi$\cos$ y privados como esferas sujetas a, e inmunes de, el control estatal, y personificando dichas limitaciones constitucionales y derechos individuales.

Quienquiera que gobierne, el problema de la tiranía continúa por resolver. La democracia -el gobierno del pueblo- puede, en sí mismo, erigirse en importante amenaza para la libertad de los individuos. Así, más que concebir un gobierno del pueblo, desde esta perspectiva, lo que es necesario para legitimar el poder gubernamental es su consentimiento. Aunque en esta visión la participación política no es un valor en sí mismo, aún puede alegarse que los intereses materiales individuales son mejor protegidos por alguna suerte de democracia, pero esta función puede ser 
llevada a cabo a través de varios tipos de representación. De esta manera, el liberalismo se adapta a la democracia por medio de la representación de diversos intereses. Además, el liberalismo puede conceptualizar el proceso democrático de toma de decisiones como un asunto de compromiso necesario entre dichos intereses. Pero las cuestiones que son susceptibles de llevarnos a conflictos que no pueden ser lidiados aun cuando haya compromiso, tales como muchos de los debates morales o religiosos, son menos fáciles de tratar, y pueden ser descartados de la agenda política e incluso del debate. A pesar de que existen muchas variantes de liberalismo, puede decirse que, en general, se adapta con mayor facilidad al modelo democrático de «mercado», en el que las preferencias individuales son agregadas, más que a un modelo de «foro», en el que las visiones son articuladas y desarrolladas en público (Elster, 1997). Como Habermas ha puesto de relieve, «el modelo liberal no depende de la autodeterminación democrática de ciudadanos que deliberan, sino de un marco constitucional para una sociedad económica a la que se supone garantice un bien común esencialmente no-político satisfaciendo planes de vida personales $\mathrm{y}$ expectativas privadas de felicidad» (Habermas, 1996: 228).

Es cierto que los liberales se han vuelto comprometidos en el cambio moderno hacia la democracia deliberativa, en la que el diálogo entre puntos de vista alternativos en un espacio público se convierte vital. Pero las consideraciones liberales sobre la democracia deliberativa (como las respaldadas por Rawls o Habermas) tienden a ser racionales y legales, o constitucionales en su enfoque, o a limitar ambos tipos de contribución al debate público y el alcance de dicha deliberación de una forma tal que rebaja la inclusividad democrática.

Por lo tanto, la tensión entre el liberalismo y la democracia resulta del miedo a la tiranía. Tanto que el concierto que el liberalismo y la democracia pueden generar conduce a poner acentos sobre el consentimiento popular, el gobierno limitado y la restricción del campo de acción de la discusión política en la práctica.

\section{Republicanismo y democracia}

El interés republicano por la libertad de los ciudadanos y su bien común ya no se conjugan a la perfección en el seno de la democracia mejor que las perspectivas liberales, aun cuando los republicanos ven al pueblo como la fuente última de la autoridad política. El republicanismo está más abierto que el liberalismo al ejercicio del poder gubernamental siempre y cuando no domine o interfiera arbitrariamente - mientras promueva los intereses de los ciųdadanos, ambos: los individuales y los comunes-. Los republicanos están interesados en que quienquiera que ejerza algún poder debe tener en cuenta el bien común. Las tensiones que surgen entre el republicanismo y la democracia resultan de la división que hay en el seno de cada ciudadano entre la dedicación al bien común o a sus intereses particulares, y del peligro que supone la dominación democrática en manos de un gobierno que persigue intereses particulares antes que comunes.

Pero el republicanismo también puede adaptarse a la democracia. Para los republicanos la participación en el autogobierno colectivo es una forma importante de autoexpresión y autodefinición —no sólo un camino para proteger los intereses individuales-. En segundo lugar, está el pensamiento en virtud del cual el bien común, en sí mismo, es mejor realizado si mucha gente tiene algo que decir en su definición. Esto puede ser fundamentado en el argumento epistémico según el cual cuantas más perspectivas sean impelidas para hacer presión sobre algún asunto de razón práctica mejor será el fallo, y también en 
la creencia de que cuanto más implicada esté la gente en un proceso de toma de decisión más probabilidades habrá de que se identifiquen con él. De este modo, la prioridad para con el bien común puede, en sí mismo, convertirse en un argumento a favor de la democracia si los ciudadanos son los mejores jueces, no sólo para sus intereses individuales, sino también para el bien común. En ambos campos puede alegarse que el pueblo debe ser capaz de hacer, y no sólo de consentir, las leyes a las cuales se sujeta. Pero lo que esto entraña en la práctica es difícil de explicar con sencillez.

Diferentes estrategias destinadas a asegurar el gobierno de ciudadanos cuidadosos de su bien común han sido adoptadas por los republicanos, de forma especial mientras los Estados crecían en tamaño y amenazaban el sentido de pertenencia a la comunidad y la dedicación al bien común entre los ciudadanos. Una estrategia - la de Madison en los Estados Unidos- enfatizó la selección de representantes virtuosos como líderes tanto como la separación de poderes, de tal forma que con el tiempo encajó en los acuerdos liberales con la democracia. Otra estrategia fue puesta de manifiesto por Rousseau. En esta visión, el bien común es realizado por el pueblo soberano deseando colectivamente la voluntad general. Pero esto crea otra tensión -une el republicanismo y la democracia sólo si el pueblo puede ser concebido como un todo, y si podemos distinguir en la práctica entre sus expresiones de voluntad general genuina (dirigidas al bien común) y el agregado de las voluntades de todos (dirigidas a bienes particulares)-. $Y$ sosteniendo que cuando aquellos que se muestran en desacuerdo con la interpretación mayoritaria de la voluntad general son invitados a cumplir, forzados para ser libres, se crea una tensión indisoluble entre la libertad como no-dominación y la libertad como participación en el autogobierno.
Habermas ha criticado justamente este enfoque como defectuoso a la hora de reconciliar la libertad y el bien común. Pero lo que no queda claro es si los problemas que él asocia a este posicionamiento son propios del republicanismo o específicos de Rousseau. Además, identifica el republicanismo con una interpretación de la política estrictamente comunitarista, como el descubrimiento de autopercepciones (self-understandings) colectivas ya existentes ${ }^{3}$.

Pero ésta no es la única manera de concebir la realización de la libertad y el bien común. El problema no es tanto la identificación del bien común como verdadero propósito de la política, sino la idea de que la expresión de un (macro-) sujeto colectivo debe ser comprendida y que, antes que algo a alcanzar mediante deliberación entre diversas perspectivas, refleja la autocomprensión existente.

\section{Enfoques republicanos} contemporáneos sobre la democracia

Por lo tanto, el renacimiento del pensamiento republicano que ha tenido lugar en los últimos veinte años, más o menos, ha intentado suscitar posibilidades alternativas en la teoría republicana. Los republicanos contemporáneos defienden un alto nivel de intervención del gobierno, hacen un llamamiento a una ciudadanía más activa y a una implicación popular en la actividad política más extensa que el consenso liberal sobre el gobierno limitado, la representación electoral de intereses y el consentimiento de los gobernados. Más que una política de consenso entre intereses, o de expresión de la voluntad colecti$v a$, enfatiza la interpretación deliberativa del bien común. No hay una manera sencilla de determinar qué hay en el bien común para una sociedad. La naturaleza y especificación de los bienes comunes realizado en política necesita ser abierto a la reflexión y deliberación por aquellos que 
son afectados por él. Pero el bien común permanece como un horizonte o idea regulativa para ser alcanzada.

Sin embargo, lo que el republicanismo contemporáneo constituye es puesto en tela de juicio; hay dos amplios tipos de enfoque, y ambos se distinguen del liberalismo en tanto que se enrolan en la democracia deliberativa. Los dos se apartan de la mayoría de los liberales rechazando la noción de libertad como no-interferencia ${ }^{4}$. Uno, que podemos denominar como «republicanismo instrumental», define la libertad como no-dominación y ve la participación en el autogobierno como principalmente un medio para el bien común y la no-dominación. El otro, que podemos llamar «republicanismo fuerte», ve la participación política como un aspecto importante (si no el último) de la libertad. En la institucionalización de la democracia, por tanto, la primera visión hace más hincapié en el espacio para cuestionar las decisiones políticas que en contribuir a ellas.

Estas diferencias podrían ser vistas como reveladoras de la incoherencia inherente al republicanismo, $o$, al menos, de su irrelevancia como enfoque alternativo útil a la democracia. Sin embargo, más que incoherente, alego que el republicanismo «instrumental» y el «fuerte» expresan dos dimensiones de un todo coherente.

\section{La consideración republicana contemporánea de la libertad: ¿no-dominación o autonomía política?}

Es cierto que una versión republicana (asociada con Pettit y Skinner) está basada en la compresión de la libertad como nodominación - una forma de protección más segura frente a las interferencias-. El republicanismo no desafía los actos de interferencia exactamente, sino el estatus de subordinación que hace que dichos actos sean posibles. Las implicaciones políticas de esta suerte de concepción de la libertad son un sistema de leyes que provee de garantías frente a las interferencias ilegítimas, para que los ciudadanos puedan ser capaces de actuar independientemente. Es el poder arbitrario, y no la ley, lo que es incompatible con la libertad. Los individuos, sin ayuda de nadie, no pueden protegerse del ejercicio del poder. Cuando son dominados están sujetos a la incertidumbre, necesitan congraciarse con el más poderoso y no pueden establecer su condición de libres públicamente. Las leyes proporcionan seguridad como no-interferencia, o una protección resistente frente a la dominación. La libertad es una condición, reconocida por todos, que recibe apoyo institucional. Creando un reconocido estatus legal que disuade la interferencia, nos inmuniza frente a las intromisiones como hacen los anticuerpos en la sangre (Pettit, 1997: 108).

Otra versión republicana tiende a nacer de la idea de autonomía, como ideal de autorrealización, basada en una percepción distinta de la libertad negativa. Para ser autónoma, una persona debe actuar de acuerdo con los propósitos que él o ella respalda. Esto define la libertad en términos de ejercicio tanto como de oportunidad. La noción de autonomía que se ha desarrollado de la idea rousseauniana de libertad descansa sobre la obediencia a la ley que uno ha hecho para sí mismo ${ }^{5}$.

Sin embargo, cabría hacer algunas matizaciones al respecto. No está claro que la libertad como no-dominación pueda ser separada de la autonomía. Realmente, Pettit no rechaza el concepto de autonomía o autogobierno sin más. Él mantiene que la no-dominación es compatible con la autonomía personal y que las instituciones republicanas la facilitan indirectamente; empero, alega que la autonomía individual no tiene que ser objeto de preocupación para el republicanismo: «se puede confiar en que la gente se encargará de su propia autonomía dado que viven bajo una administración donde son protegidos de la 
dominación frente a terceras personas» (Pettit, 1997: 83).

Mas la autonomía personal está afectada por nuestra vulnerabilidad recíproca; así, como nadie puede ser dueño y señor de su propia vida completamente, la libertad puede ser mejor entendida como autor parcial de la vida de cada uno (Raz, 1986: 155). La libertad es promovida cuando las personas pueden cooperar para alcanzar sus objetivos más allá de la capacidad de los individuos en su singularidad. Es reducida cuando fracasan a la hora de hacerlo. Podemos decir que la autonomía es intensificada si los ciudadanos tienen algo que decir a la hora de dar forma a las prácticas a través de las cuales persiguen sus vidas en la sociedad. La autonomía no puede ser entendida en términos estrictamente privados. Así, la autonomía política puede ser vista como la extensión natural de la autonomía personal. De este modo, Habermas ve la autonomía privada y la pública como igualmente primordiales, o fundamentales:

«No es asunto de la autonomía pública complementar y permanecer ajena a la autonomía privada, sino más bien la de una interna, esto es, conceptualmente necesaria conexión entre ellas. En el análisis final, las personas privadas legales ni siquiera pueden alcanzar el disfrute de libertades iguales a menos que ellos mismos, ejercitando conjuntamente su autonomía como ciudadanos, lleguen a una comprensión nítida sobre qué intereses y criterios son justificados, y con respecto a qué cosas iguales pueden ser tratadas ecuánimemente y cosas diferentes desigualmente en algunos casos particulares» (Habermas, 1994: 113) ${ }^{6}$.

Si la libertad es entendida como un ideal a ser promocionado, más que una restricción a ser observada, la no-dominación parece apuntar más allá de sí misma, no al control total, sino a la participación en la determinación de las condiciones de la vida social. Podríamos ver la no-supremacía como una precondición para algunos grados de autodeterminación en la «autonomía política republicana» ${ }^{7}$ La autonomía puede no realizarse plenamente en política, pero necesita una expresión política, y tampoco puede ser satisfecha completamente fuera de la política. Tiene dimensiones políticas y personales. Los argumentos para la no-dominación y la autonomía personal no son enteramente independientes de los argumentos para la autonomía política.

\section{El enfoque republicano}

contemporáneo sobre la democracia: ¿impugnación o participación?

El segundo asunto que parece surgir es el valor y extensión de la participación deseada por la ciudadanía.

Debe hacerse notar que los republicanos fueron los pioneros en la defensa del Estado de Derecho, o más tradicionalmente «del imperio de las leyes y no de los hombres» (Harrington, 1992: 8). Sin embargo, aquellos que creen en la participación pueden ver que la única manera en la que el Estado de Derecho puede ser efectivo es en un amplio esquema de poderes separados, si «los funcionarios políticos y judiciales, así como las políticas y las instituciones son receptivos a la legislación, entonces los ciudadanos verían reflejados en la experiencia los efectos del derecho» (Bellamy, 2001: 248).

Desde la visión instrumental, el republicanismo no necesita implicar una amplia participación de la ciudadanía, ni, incluso, la primacía del debate público: «La democracia no es, por sí, un asunto colectivo; no es intrínsecamente una cuestión de control activo, tampoco un modo de sistema que restringe la toma de decisiones a fracciones que están disponibles a escrutinio e influencia pública» (Pettit, 2000: 140). Pettit critica duramente versiones de republicanismo que realzan la participación y control colectivo, y justifica la tiranía de la mayoría por miedo.

Si valorar la participación depende de formarse una idea de autogobierno colecti- 
vo sobre un modelo unitario rousseauniano que sea expresión singular de la voluntad general sobre todo asunto, donde toda disidencia es subversiva, habría una verdadera dificultad. Sin embargo, el autogobierno colectivo no debe ser considerado como un modelo unitario.

Abundando en dicha idea, es posible concebir la participación política como intrínsecamente de valor sin por ello reivindicar que es el aspecto más valioso de la naturaleza humana o la más alta realización de la misma. Puede tener un objetivo más modesto. Como Pitkin ha puesto de relieve, «sólo la ciudadanía nos permite hacernos cargo y responsabilizarnos de manera conjunta de las fuerzas sociales que de otra manera dominarían nuestras vidas y limitarían nuestras opciones, aun cuando las produzcamos nosotros» (Pitkin, 1981:334).

Si el principio de no-dominación es tomado como el núcleo del republicanismo, podría ser alegado que la posibilidad de impugnar todas las decisiones es la pauta más importante para diseñar instituciones deliberativas. De esta manera, para Pettit, la cuestión principal es que el gobierno debería trazar los intereses de los ciudadanos de una manera tal que las instituciones deberían ser responsables ${ }^{8}$. Esto va más allá del clásico énfasis liberal en el consentimiento, el gobierno limitado y la representación electoral de intereses.

Mientras una desconfianza en las grandes mayorías le conduce a argumentar que ciertas áreas deberían ser despolitizadas, asignando ciertas decisiones a tribunales expertos y comisiones, la participación debiera limitarse a cuestionar y no a fomentar las decisiones (Pettit, 1997: 194). No obstante, Pettit amplía esta visión y excluye una participación más activa, tal como sería el caso de los referenda promovidos por los ciudadanos y el poder de veto (Pettit, 1999) ${ }^{9}$. Y puede ser alegado que la no-dominación puede acarrear unos intentos más activos a la hora de sacar a relucir asuntos, el consultar a los ciudadanos y el aumento de la competición electoral que Pettit sostiene (Maynor, 2003).

Ambos, liberales y republicanos, tienen razones para dudar de la democracia como la soberanía del pueblo en cualquier simple interpretación holista. La idea de Pettit de la no-dominación es un complemento esencial a la idea de libertad como participación en el autogobierno. Mientras que los republicanos clásicos estaban al tanto de las distorsiones que resultan cuando los participantes son sometidos a la voluntad de otros, han sido a menudo acusados de ser ciegos a otros ejercicios de poder. Un sistema de toma de decisiones colectivo sin garantías contra la dominación puede ser, simplemente, el reflejo de la voluntad de aquellos que detentan posiciones dominantes y refuerzan su poder para satisfacer sus propios intereses.

De hecho, los republicanos contemporáneos tienden a converger en un modelo de participación democrática como compromiso deliberativo antes que en un contrato de intereses individuales, propio de las consideraciones liberales sobre la democracia, o como la encarnación de un deseo colectivo. Uno de los puntos de vista republicanos subraya la habilidad para discutir decisiones; otro, la habilidad para contribuir al debate. Ambos encajan mejor con una visión de la democracia como un foro o esfera pública en la que alternativos enfoques son expuestos, escuchados y considerados entre diferentes individuos. Los dos ponen de relieve la manera en la que estructuras legales deben ser puestas en paralelo por el compromiso cívico de los ciudadanos.

El republicanismo democrático puede proyectar un rol de ciudadanos activos preocupados por el bien común, aunque sólo en un proceso deliberativo carente de la intención de imponer un deseo colectivo 0 un ideal de autogobierno. El objetivo republicano de determinar el bien común y 
alentar el compromiso cívico ofrece a la deliberación una perspectiva particular y una importancia distinta de, por ejemplo, su posible rol de prestar a los intereses de los individuos una mayor atención. Además, desde esta visión, la igualdad de los ciudadanos en el contexto de diversidad puede ser mejor alcanzada promocionando una deliberación pública de mayor poder aglutinador preferible a la más limitada concepción liberal de la deliberación, en la que la diferencia privada es agrupada, y la igualdad ciudadana garantizada por un Estado neutral y la tolerancia para con la diferencia privada. De este modo, el republicanismo no debería ser confundido con el comunitarismo, ni tampoco, como un autor ha señalado, ser absorbido por el liberalismo (Dryzek, 2000: 27). El argumento aquí mostrado es que el republicanismo ofrece una perspectiva diferente de la democracia en su preocupación por el bien común, su asociación de la libertad con la no-dominación y la participación en el autogobierno antes que una principal preocupación por la limitación del gobierno.

\section{El desafio de la democracia transnacional}

Aun cuando muchas de las críticas que han sido dirigidas hacia el pensamiento republicano pueden ser combatidas, éste se enfrenta a un reto mayor al cuestionarse si tiene recursos para abordar los problemas de la democracia a nivel transnacional o global. Hoy en día, la realidad de la globalización es que, a pesar de la creciente interdependencia que entraña, implica un desgaste de la política pública vis a vis los intereses económicos privados y el poder, y parece minar cualquier posibilidad de una segura no-dominación, autogobierno colectivo, o un compromiso social más amplio entre los ciudadanos. Podemos recordar que la defensa que Cicerón hace de la república romana en su De Officiis, o las esperanzas que Maquiavelo alberga en Florencia en los Discorsi, fueron escritos precisamente cuando estas repúblicas eran sustituidas por un imperio y un ducado respectivamente. ¿Podría ser el renacimiento del republicanismo contemporáneo otro ejemplo de la lechuza de Minerva alzando el vuelo al amanecer? Si el republicanismo trata de reclamar al Estado poder para los ciudadanos, ¿qué negociación podrá haber cuando no hay Estado en el mundo del cual recuperar poder? Si trata de reavivar el espíritu cívico y la participación, ¿qué donde no hay comunidad ni demos? Si trata de prevenir la no-dominación, ¿qué donde no hay un sistema legal internacional efectivo?

La primera cuestión que hay que abordar es el de la magnitud. Se ha dicho que no puede haber democracia transnacional porque el número de los implicados puede diluir la voz de cualquier ciudadano tanto como para hacerla ineficaz por entero. Pero podría decirse, al respecto, que tan sólo hay una diferencia de grado entre la política nacional y la internacional. En cualquier caso, si el objetivo no es tanto discernir una voluntad colectiva como tener en cuenta muchas contribuciones a la deliberación, su número no supone un gran problema; lo que es esencial es un foro público $o$, más bien, múltiples niveles de espacios públicos en los que los ciudadanos puedan ser oídos. Como dice Bohman, «una vez que pensemos la participación como mediada a través de varias esferas públicas, las ventajas deliberativas de la diversidad y numerosidad para la responsabilidad y para el examen de perspectivas de segundo orden pesarán, de lejos, más que la pérdida de influencia directa» (Bohman, 2004: 350).

Un segundo asunto es si el republicanismo es particularista por naturaleza, una cuestión de promocionar un código compartido y los intereses particulares de una comunidad. Sin embargo, contra Walzer, sus defensores contemporáneos entienden 
el republicanismo como promotor, no sólo de creencias locales compartidas, sino de valores universales de libertad como nodominación, autogobierno y un compromiso social más amplio. Éstos son siempre realizados a través del autogobierno en contextos particulares y de maneras específicas, y requieren formulaciones más sensibles al contexto que otros enfoques de las instituciones políticas y la política. En tanto que restringidos, principalmente, a discutir la política al nivel del Estadonación, ni los republicanos fuertes (como Arendt) ni los republicanos instrumentales (como Pettit) ven su concepción de la política y la ciudadanía como inherentemente exclusiva. De esta manera, el republicanismo es compatible con un cosmopolitismo moral débil al reconocer compromisos locales tanto como universales. Mientras la ciudadanía republicana y sus obligaciones estén basadas en la interdependencia más que en el denominador común de la humanidad, la comunidad política republicana y la ciudadanía son, por lo tanto, potencialmente extensibles.

Aun cuando a la comunidad republicana le sea posible expandirse, puede ser dicho que cualquier tipo de democracia requiere un demos, y en el presente no existe demos mundial alguno. Lo que esto implica es que la existencia de un demos unificado es una precondición para la democracia. Más que el demos pre-político que está en la base de los Estadonación existentes, debemos reconocer que el demos o nación se ha desarrollado históricamente desde agrupaciones locales cuando han estado bajo el control de instituciones legales y políticas comunes, $\mathrm{y}$, a menudo, han sido realmente creadas por éstas.

Sin embargo, puede alegarse que tampoco existe ninguna institución, política $o$ legal, internacional efectiva. Si los republicanos están interesados en realizar la libertad para ciudadanos que comparten un mismo sino porque son sujetos de una misma autoridad, en el mundo, hoy en día, no existe semejante autoridad internacional global. Por el contrario, sería un error pensar que el republicanismo es relevante para la política global sólo hasta el punto en que pueda abordarse algún tipo de institución política global existente. Por una parte, la creciente interdependencia significa que hay bienes comunes y peligros comunes - de manera evidente aquellos que se refieren al medioambiente- compartidos por miembros de diferentes Estados. La actual configuración de la política mundial yerra a la hora de promover los bienes comunes y disminuir los riesgos, y favorece la protección de los intereses particulares de una forma tal que, dicho en términos republicanos, constituye una sistemática corrupción. Desde un punto de vista, esto puede generar un sentimiento de destino común (Dryzek, 2000). Por lo tanto, también puede ser posible concebir una evolución hacia una ciudadanía cosmopolita desde la base a través del desarrollo de crecientes tramas de relaciones, o áreas de solapamiento económico, medioambiental o cultural interdependientes. Sin embargo, identificarse con los bienes comunes que conlleva puede ser difícil para las personas, de manera especial cuando se mantienen en situaciones tan diferentes con respecto a los beneficios y las responsabilidades que entraña.

Desde otro punto de vista, es la dominación, como hecho, la que nos ofrece la clave. De esta manera, Bohman argumenta que mientras la global interdependencia económica puede no constituir un destino común entre los habitantes del mundo, es, precisamente, la manera en que el impacto diferencial de la globalización conduce a un creciente potencial para la dominación lo que hace pertinente el enfoque republicano. Por ejemplo, la no-voluntaria inclusión de muchos en los esquemas cooperativos, por ejemplo, de los mercados financieros internacionales, constituye dominación y exige de estructuras legales 
y respuesta política. En tanto no haya semejante Estado mundial, o una única autoridad política, las instituciones internacionales de distinto tipo constituyen una red de cuasi autoridad con potencial para resistir tanto la dominación ejercida por otros actores, como para amenazarse mutuamente. Las instituciones internacionales de derechos humanos, tales como el Tribunal de Justicia Internacional, constituyen una incipiente comunidad política mundial de ciudadanos; sin embargo, se requiere un mayor desarrollo político para lograr mayores cotas de publicidad y responsabilidad. Bohman concluye que «desde la perspectiva normativa de la libertad como no-dominación, la globalización no es sólo un fenómeno negativo, sino que también crea condiciones favorables que hacen de la realización de semejante comunidad política una extensión realista de las posibilidades actuales» (Bohman, 2004: 351).

Para otros, el marco de las estructuras internacionales legales es, en la práctica, menos efectivo que el antagónico poder político de los Estados-nación actuales. Por esta razón, aunque la república no tiene que ser identificada con el Estadonación, puede ser alegado que lo que se requiere es reforzar y extender los Estadonación, las instituciones interestatales y el compromiso ciudadano. Por lo tanto, Slaughter sostiene que, «en tanto que un público global concreto es un pensamiento cosmopolita para un futuro previsible, el extender la existencia de las instituciones interestatales, junto con una genuina reflexión ciudadana sobre política global y las condiciones necesitadas para la libertad cívica, son esenciales para un enfoque republicano que es capaz de desarrollar la no-dominación en un contexto de globalización» (Slaughter, 2005: 206).

Sin embargo, el objetivo de los republicanos no tiene que ser un sistema unificado de autoridad política que sustituya a los actuales Estados. Tales esquemas de democracia cosmopolita pueden ser considerados potencialmente tiránicos y faltos de compromiso popular. Ya hemos visto que el fin no es el ejercicio popular directo de la soberanía, sino el limitar ambos, el imperium público y dominium privado, e implicar a los ciudadanos en su propio autogobierno a varios niveles. De esta guisa, lo que se requiere es complejo: discusión a diferentes niveles y participación deliberativa en espacios públicos antes que la soberanía de cualquier individuo colectivo en la toma de decisiones. Este hecho también es coherente con una visión contemporánea de la política como no limitada por el ejercicio de un poder estatal centralizado, sino como contestación al ejercicio del poder en toda área de la vida, y como el tener qué decir a la hora de determinar las condiciones de la vida de uno mismo. Más a tono con las preocupaciones republicanas está el argumento en virtud del cual las actuales instituciones internacionales deberían ser democratizadas haciéndolas más públicas y responsables.

Por lo tanto, a pesar de sus diferencias, los republicanos ofrecen argumentos distintivos sobre la cuestión de la democracia transnacional que enfatizan de manera concurrente la necesidad de responder a una interdependencia in crescendo, de oponerse a una dominación arbitraria - ya sea del Estado o de actores no estatales-. y de promover el desarrollo de esferas públicas apropiadas junto a la participación en ellas.

\section{BIBLIOGRAFÍA}

ABIZADEH, A. (2002): «Does liberal democracy presuppose a cultural nation? Four arguments», American Political Science Review, núm. 96, pp. 495-509.

ALlen, A., y REGAN, M. (eds.) (1998): Debating Democracy's Discontents, Oxford, Oxford University Press. 
AREnDT, H. (1958): The Human Condition, Chicago, Chicago University Press.

- (1977): On Revolution, Nueva York, Penguin.

BARBER, B. (1984): Strong Democracy, Berkeley y Londres, University of California Press.

BELLAMY, R. (2001): «The rule of law and the rule of persons», Critical Review of International Social and Political Philosophy, núm. 44, pp. 221-251.

Bellamy, R., y CAstiglione, D. (1998): «Between cosmopolis and community: three model of rights and democracy within de EU», en D. ARCHIBUGI, D. HelD y M. KOHLER (eds.), Re-Imagining Political Community, Cambridge, Polity.

BOHMAN, J. (2001): «Cosmopolitan republicanism: citizenship, freedom and global political authority», The Monist, núm. 84, pp. 13-21.

Bohman, J., y ReHG, W. (1997): Deliberative Democracy: Essays on Reason and Politics, Cambridge, MIT Press.

BRUGGeR, B. (1999): Republican Theory in Political Thought: Virtuous or Virtual?, Nueva York y Basingstoke, Macmillan.

DAHL, R. (1989): Democracy and its Critics, New Haven, Yale University Press.

DRYZEK, J. (1999): Discursive Democracy: Politics, Policy and Political Science, Nueva York, CPU.

- (2000): Deliberative Democracy and Beyond, Oxford, Oxford University Press.

ElSTER, J. (1997): «The market and the forum», en J. BOHMAN y W. REHG, Deliberative Democracy: Essays on Reason and Politics, Cambridge, MIT Press.

Habermas, J. (1994): «Three Models of Democracy», Constellations, núm. 1, pp. 1-10.

- (1996): Between Facts and Norms, Cambridge, Polity Press.
HarRington, J. (1992): The Commonwealth of Oceana and a System of Politics, Cambridge, CPU.

HONOHAN, I. (2000): «Dealing with difference: the republican public-private distinction», en M. BAGHRAMIAN y A. INGRAM (eds.), Pluralism: the Philosophy and Politics of Difference.

- (2001): «Friends, strangers or countrymen? The ties between citizens as colleagues», Political Studies, núm. 49, pp. 51-69.

- (2002): Civic Republicanism, Londres y Nueva York, Routledge.

ISAAC, J. (1988): «Republicanism vs. Liberalism?: a reconsideration», History of Political Thought, núm. 9, p. 349.

KYMLICKA, W. (2002): Contemporary Political Philosophy: an Introduction, (second edition), Oxford, Oxford University Press.

KyMlickA, W., y NORMAN, W. (1995): «The return of the citizen: a survey of recent work on citizenship theory», Ethics, núm. 104, pp. 352-381.

MachIavelli, N. (1983): The Discourses (ed. B. Crick), Harmondsworth, Penguin.

MAYNOR, J. (2003): Republicanism in the Modern World, Cambridge, Polity.

MiCHELMAN, F. (1986): «Foreword: traces of self government», Harvard Law Review, núm. 100, pp. 4-77.

- (1988): «Law's Republic», Yale Law Journal, 97, 8, pp. 1493-1537.

OldFIELD, A. (1990): Citizenship and Community, Londres, Routledge.

PATTEN, A. (1996): «The republican critique of liberalism», British Journal of Political Science, núm. 26, pp. 25-44.

PETTT, P. (1997): Republicanism, Oxford, Oxford University Press.

- (1999): «Republican freedom and contestatory democratization", en I. SHAPIRO y C. HACKER-CORDON (eds.), Democracy's Values, Cambridge, CPU. 
- (2000): «Democracy, electoral and contestatory", en I. SHAPIRO y S. MACEdo (eds.), Designing Democratic Institutions, New York, New York University Press.

PitKIN, H. (1981): «Justice: on relating private and public», Political Theory, núm. 3, pp. 327-352.

-: Fortune is Woman: Gender and Politics in the Thought of Niccolo Machiavelli, Berkeley, University of California Press.

Rawls, J. (1971): A Theory of Justice, Oxford, Oxford University Press.

- (1993): Political Liberalism, New York, Columbia University Press.

RAZ, J. (1986): The Morality of Freedom, Oxford, Clarendom Press.

Rousseau, J. J. (1964): Ouvres Complètes, París, Gallimard.

- (1969): The Social Contract, Harmondsworth, Penguin.

- (1974): Émile, Londres, Dent.

- The Social Contract and The Discourses, Londres, Dent.

SANDEl, M. (1996): Democracy's Discontent, Cambridge, Harvard University Press.

- (1998): «Reply to critics», en A. ALLEN y M. REGAN (eds.), Debating Democracy's Discontent, Oxford, Oxford University Press.
SHAPIRO, I., y MACEDO, S. (eds.) (2000): Designing Democratic Institutions, New York, New York University Press.

SLAUGHTER, S. (2005): Liberty beyond Neo-liberalism: a republican critique of liberal governance in a globalizing age, Basingstoke, Palgrave Macmillan.

SKINNER, Q. (1990): «The republican idea of political liberty», en G. Bock, Q. SKINNER y M. VIROLI (eds.), Machiavelli and Republicanism, Cambridge, CPU.

- (1998): Liberty before Liberalism, Cambridge, CPU.

SUSTEIN, C. R. (1985): «Interest groups in American public law», Stanford Law Review, núm. 38, pp. 29-87.

- (1988): «Beyond the republican revival», Yale Law Journal, núm. 97, pp. $1539-1590$.

- (1991): «Preferences and politics», Philosophy and Public Affairs.

TAYloR, C. (1985): Philosophical Papers, Cambridge, CPU.

- (1989): Sources of the Self, Cambridge, CPU.

- (1995): Philosophical Arguments Cambridge, Harvard University Press.

WALZER, M. (1985): Spheres of Justice, Oxford, Basil Blackwell.

- (1992): «The civil society argument», en C. Moufre (ed.), Dimensions of Radical Democracy, Londres, Verso.

NOTAS

1 Una primera versión de este trabajo fue presentada en BICOD (Beijing Internacional Conference on Democracy, Chinese Academy of the Social Sciences) en abril de 2004. Algunos de los argumentos que se presentan en la primera parte han sido desarrollados con mayor detalle en mi Civic Republicanism (2002). Versión castellana de Jorge del Palacio.

2 Algunos autores republicanos, así como algunos de sus críticos, yerran a la hora de distinguir con suficiente claridad las ideas republicanas y comunitaristas (Walzer, Sandel)

3 Habermas interpreta la tradición republicana como el ramal que va exclusivamente de Aristóteles hasta Rousseau y en el que la libertad se concibe en términos de autolegislación (self-legislating) de los ciudadanos, lo que es distinto de la libertad personal enfatizada por los liberales. Él ve el republicanismo contemporáneo en términos comunitaristas, como un proceso «ético» de realización o descubrimiento de bienes comunes ya existentes, y adopta una postura crítica hacia dicha concepción política. Pero, de hecho, su propia «teoría del discurso» comparte con los defensores de la autonomía política republicana el énfasis (más o menos directo) en la participación en el autogobierno como parte de la autonomía (Habermas, 1994). 


\begin{abstract}
4 Es cierto que algunos relatos sobre el republicanismo lo han presentado como un medio instrumental para defender la libertad negativa de las interferencias, y que son difíciles de distinguir del liberalismo. No obstante, uno de éstos, al menos, ha progresado hacia la aceptación de lo esencial del enfoque de la no-dominación. (Compárese Skinner 1990, 1998.)

5 Una definición más completa concibe las personas autónomas como aquellas que «adoptan proyectos personales, desarrollan relaciones y aceptan compromisos para con causas a través de las que su integridad personal, sentido de dignidad y amor propio se concretan» (Raz, 1986: 154).

${ }^{6}$ Habermas también fomenta una teoría de la autonomía política como parte del autogobierno colectivo, viéndola como paralela a la autonomía privada y como dos dimensiones irreductibles de la libertad. «La autonomía política es un fin en sí mismo que puede ser realizado no por individuos singulares persiguiendo sus propios intereses en privado, sino sólo por todos juntos en una práctica compartida intersubjetivamente» (Habermas, 1996: 498).

7 La manera en la que no sólo la dominación, sino también la impotencia, tienden a socavar la autonomía ha sido recientemente destacado por feministas y otros. A ello se alude en la respuesta de Wollstone-
\end{abstract}

craft a Rousseau: «Yo no deseo que ellos tengan poder sobre los hombres, sino sobre ellos mismos» (Wollstonecraft, 1992: 156).

8 Los representantes de todos los intereses en la sociedad deberían ser elegidos por un amplio electorado; el poder debería ser separado entre un cuerpo legislativo con dos cámaras, cada una elegida sobre una base diferente, y un poder judicial fuerte para el mantenimiento de los derechos constitucionales. Debería haber libertad de legislación de información, un sistema de defensores del pueblo y otros procesos de apelación en un amplio ámbito de áreas. Debería haber, asimismo, previsiones para representaciones especiales en caso de que fueran necesitadas y el proceso será fortalecido si existe una variedad de movimientos sociales (Pettit, 1997: 193; 1999).

${ }^{9}$ Desde esta perspectiva, el rol de la ciudadanía en su propio gobierno es más bien el de varios directores que el de coautores de decisiones políticas (Pettit, 2000). A pesar de ello, el punto de vista de Pettit se concentra más en la toma de decisión que en la deliberación. Puede ser cierto que las pequeñas instituciones sean más efectivas que las grandes a la hora de tomar de decisiones; sin embargo, las decisiones que más información aglutinan es muy probable que sean mejores. 